\title{
EVIDÊNCIAS DE VALIDADE DO TESTE DE PFISTER: AGRESSIVIDADE E IRRITABILIDADE EM MOTORISTAS
}

\author{
Joneia Mayumi Tawamoto \\ Especialista em Dependências Químicas, em Trânsito: Gestão da Mobilidade Urbana e Saúde \\ Pública pela PUCPR e Psicologia do Trânsito pelo CFP, \\ Mestre em Psicologia pela Universidade São Francisco
}

Cláudio Garcia Capitão

Especialista em Psicologia Clínica e em Hospitalar, Mestre pela PUCSP, Doutor pela UNICAMP, PósDoutorado em Psicologia Clínica PUCSP. Docente do curso de Psicologia e do Programa de Pósgraduação Sricto Sensu da Universidade São Francisco

\begin{abstract}
Resumo
Objetivou-se pelo presente estudo comparar os indicadores de agressividade e irritabilidade, encontradas por meio do Teste das Pirâmides Coloridas de Pfister (TPC), entre os motoristas infratores e não-infratores; correlacionar os indicadores de agressividade e irritabilidade do TPC dos motoristas com os resultados obtidos do Inventário de Habilidade do Motorista (IHM), Questionário do Comportamento do Motorista (QCM) e Escala de Irritabilidade do Motorista (EIM). O TPC permite a avaliação da dinâmica da personalidade e o nível de maturidade das suas expressões no mundo das relações. Participaram da pesquisa 100 motoristas, da Cidade de Curitiba, divididos em dois grupos. O primeiro foi composto por 50 motoristas infratores que realizaram o Curso de Reciclagem e que obtiveram pontuação por ultrapassar o limite de velocidade três vezes em um ano. O segundo grupo composto por 50 motoristas que renovaram a $\mathrm{CNH}$, possuem a carteira há mais de cinco anos, não cometerem nenhum tipo de infração, não assumiram a pontuação de outro motorista e não se envolveram em acidentes como motorista. Para a análise do TPC foram considerados o Vermelho aumentado, devido à tonalidade 2, sem a presença de indicadores de contenção; Amarelo aumentado, sem a síndrome do dinamismo; Verde rebaixado e Vermelho aumentado; Síndrome do Conflito Interno, Vermelho tonalidade 2 e Violeta tonalidade 2, também sem indicadores de contenção, e a Síndrome de Histeria. Nos resultados foram encontradas correlações significativas estatisticamente com a dupla Verde rebaixada e Vermelho aumentado e a Síndrome do Conflito Interno, indicado que TPC evidenciou validade concorrente por meio das correlações com QCM e EIM.
\end{abstract}

Palavras-chave: avaliação psicológica, psicologia do trânsito, Teste das Pirâmides Coloridas de Pfister, avaliação de motoristas.

\section{EVIDENCE OF VALIDITY OF PFISTER'S TEST: AGGRESSIVENESS AND IRRITABILITY IN DRIVERS}

\begin{abstract}
This present study aimed to compare the indicators of aggressiveness and irritability, found through Pfister Colored Pyramid Test (CPT), between the infracting and noninfracting drivers; to correlate the indicators of aggressiveness and irritability of the drivers' CPT with the results obtained from the Driver Skill Inventory (DSI), Driver Behavior Questionnaire (DBQ) and Driver Irritability Scale (DIS). The CPT allows assessing the personality dynamics and the level of maturity of its expressions in the world of relationships. One hundred drivers from the city of Curitiba, who were divided in two groups, participated in the research. The first was composed by 50 infracting drivers that accomplished the Refresher Driving Course and who obtained points for driving over the speed limit three times in one year. The second group was composed by 50 drivers who have renewed their driver's license, have their driver's license for more than five years, didn't commit any kind of infraction, didn't assume another
\end{abstract}


driver's points and weren't involved in accidents as drivers. For the CPT analysis, it was considered: an increase in the red color, due to nuance 2, without the presence of contention indicators; an increase in the yellow color, without the dynamism syndrome; a decrease in the green color and an increase in the red color; Internal Conflict Syndrome, nuance 2 of red and nuance 2 of violet, also without contention indicators, and the Hysteria Syndrome. In the results, significant statistic correlations were found with the pair decreased green color and increased red color and the Internal Conflict Syndrome, indicating that CPT evidenced competitive validity through the correlations with DBQ and DIS.

Keywords: psychological assessment, traffic psychology, Pfister Colored Pyramid Test, drivers assessment.

\section{EVIDENCIAS DE VALIDEZ DEL TEST DE PFISTER: AGRESIVIDAD E IRRITABILIDAD EN CONDUCTORES}

\section{Resumen}

El objetivo del presente estudio fue comparar los indicadores de agresividad e irritabilidad, que se encuentra a través de la prueba de color Pirámide de Pfister (TPC) entre los conductores infractores y no infractores; correlación entre los indicadores de agresividad y la irritabilidad de los controladores con el TPC resultados de la habilidad del conductor de inventario (HMI), el controlador de comportamiento Cuestionario (PEM) y el controlador Irritabilidad Escala (EIM). EI CPC permite la evaluación de la dinámica de la personalidad y nivel de madurez de su expresión en las relaciones mundiales. 100 conductores participaron en la encuesta, la ciudad de Curitiba, divididos en dos grupos. El primero estaba compuesto por 50 conductores infractores que tomaron el curso de actualización y anotó por exceder el límite de velocidad tres veces en un año. El segundo grupo consta de 50 conductores que renovaron $\mathrm{CNH}$, que la cartera de más de cinco años, no cometer ningún tipo de infracción, se tomó decenas de otro conductor y no implicados en accidentes como conductor. Para el análisis de la CPT se considera la Red aumentó debido al segundo tono, sin la presencia de indicadores de contención; mayor dinamismo amarillo sin el síndrome, verde y rojo degradado mayor; Síndrome de conflicto interno 2 rojas tono y el matiz violeta 2, también sin los indicadores de la discordia, y el síndrome de la histeria. Los resultados fueron estadísticamente uma correlación significativa com La doble verde y rojo sube y baja El síndrome de conflicto interno, se indica que El TPC demonstro La validez concurrente a través de correlaciones com QCM y EIM.

Palabras clave: evaluación psicológica, psicología del tráfico, Color Pirámide de prueba de Pfister, evaluación de los conductores.

\section{INTRODUÇÃO}

Após a Segunda Guerra Mundial, o automóvel particular transformou-se em um fenômeno de massa em todo o mundo, tornando-se artigo de consumo e símbolo de status social. Esse fenômeno foi impulsionado pelo forte aparato de propagandas da economia capitalista, que destacavam como vantagem a mobilidade individual (Marin \& Queiroz, 2000). A produção mundial de automóveis cresceu de 11 para 53 milhões entre 1950 e 1995, porém, o sistema viário e o planejamento urbano não acompanharam esse crescimento (TapiaGranados, 1998). Na década de 90, outro fator que contribuiu para o crescimento de veículos particulares na malha viária do Brasil, foi a diminuição na qualidade do transporte público urbano e a criação dos carros populares com 
menor valor de mercado, tornando-se comum encontrar famílias em que vários membros possuíam cada um seu veículo (Mauro, 2001).

Decorrente dessas circunstâncias, problemas com poluição sonora e atmosférica, aumento do tempo de percurso e engarrafamentos transformaramse em fontes responsáveis pela crescente agressividade dos motoristas e pela decrescente qualidade de vida em meio urbano (Tapia-Granados, 1998). Juntamente com a incorporação do automóvel ao cotidiano das comunidades, surge outro importante problema, os acidentes de trânsito (AT) (Marin \& Queiroz, 2000).

Os acidentes de trânsito destacaram-se como um dos problemas mundiais de saúde na década de 70, quando a Organização Mundial da Saúde (OMS, 1976) apresentou na Conferência Européia The Epidemiology of Road Traffic Accidents, um levantamento sobre este tema. No ano de 1996 o Acidente de Trânsito (AT) foi incluído na Classificação Estatística de Doenças e Problemas Relacionados à Saúde (CID-10). Os dados da OMS indicam que 1,2 milhões de pessoas morrem a cada ano nas estradas e cerca de 50 milhões sofreram lesões ocasionadas pelos AT (OMS, 2004). No Brasil, o número de vítimas de acidentes de trânsito tem preocupado pela sua crescente representatividade, o Ministério da Saúde (2004) aponta como a terceira causa de óbitos, atrás das neoplasias e das doenças do aparelho circulatório.

Outro problema nesse contexto são as lesões e às deficiências físicas decorrentes dos AT (Almeida \& Freitas, 1995; Sallum \& Koizume, 1999; Weyll, Silveira \& Fonseca, 2005), a Organização Pan-Americana de Saúde - (1994) afirma que em torno de $6 \%$ das deficiências físicas no mundo são causadas por esse tipo de acidente. Destaca-se que as essas deficiências trazem graves danos ao indivíduo (financeiros, familiares, de locomoção, profissionais) e à sociedade (gastos hospitalares, diminuição de produção, custos previdenciários). Os prejuízos relacionados aos AT ainda se estendem a questões econômicas, interferindo nos recursos à saúde, com a ocupação de leitos hospitalares e nas despesas para o atendimento das vítimas (Centro de Pesquisa em Educação e Prevenção da rede SARAH, 2000; Instituto de Pesquisa Econômica Aplicada, 2006).

O custo mundial de atendimentos aos acidentados no trânsito segundo a OMS (2004), é de aproximadamente 518 milhões de dólares em um ano, os gastos são estimado conforme as condições do desenvolvimento do país. Nos 
considerados baixo em desenvolvimento, estima-se que se gasta em torno de $1 \%$ do produto interno bruto (PIB), nos emergentes $1,5 \%$ e nos desenvolvidos 2\%. Há uma projeção de que o AT será a terceira causa de óbito no mundo com uma probabilidade de aumento com cerca de $70 \%$ durante os próximos 20 anos, salvo se houver políticas de prevenção eficazes (OMS, 2004).

No Brasil, várias medidas têm sido adotadas para contenção dessa problemática, com a implantação do Código de Trânsito Brasileiro (CTB) em 1997, tornou-se possível identificar as infrações reincidentes devido ao controle exercido pelos órgãos competentes. Essa questão se evidenciou por alguns levantamentos demonstrarem que o excesso de velocidade e o estacionamento irregular eram as mais constantes (Departamento de Trânsito do Paraná, 2004; Macêdo, 2005). A pesquisa de Prado (2005) confirma que o excesso de velocidade, 54,3\% seguida do estacionamento em desacordo com a sinalização, $32,6 \%$ foram as infrações mais cometidas entre 313 indivíduos pesquisados.

É importante destacar que a conduta de exceder a velocidade implica em aumentar a probabilidade das falhas humanas no trânsito, uma vez que o condutor limita o tempo de processamento das informações para a tomada de decisão. Ainda, no caso de um acidente, há maior possibilidade de aumentar a gravidade das lesões tanto para os ocupantes dos veículos, quanto para os outros usuários da via. Almeida e Freitas (1995) verificaram 277 laudos de pessoas envolvidas em acidentes. 57\% (28) dos que foram a óbito eram pedestres, 32,5\% (16) condutores e 10,5\% (5) acompanhantes. Embora o excesso de velocidade possa não ter sido a principal causa dos acidentes, foi constatado que, quanto maior a velocidade, maior a freqüência de fraturas de órgãos, tendo uma diferença significativa em relação a velocidades menores $\left(x^{2} \rho=0,005\right)$.

Para coibir essas ações o CTB (1997) penaliza o infrator por meio de monitoramento os condutores que excederem a velocidade da via em até $20 \%$, com quatro pontos na $\mathrm{CNH}$, velocidades entre $20 \%$ e $50 \%$ acima da máxima permitida com cinco pontos e velocidade acima de $50 \%$ da máxima permitida, com sete pontos. Respectivamente pelo CTB (1997), essas infrações são consideradas, média, grave e gravíssima. Como o Estado suspende a Carteira Nacional de Habilitação ao infrator que atingir a contagem de vinte pontos em um ano, essa medida permite que o infrator reincidente, tenha o direito de dirigir enquanto o mesmo não acumule a pontuação necessária no período de 12 
meses. Esse fato pressupõe que os motoristas com tendência a um comportamento de risco, por exceder a velocidade, permaneçam no trânsito aumentando a probabilidade cometer mais infrações e em se envolver em acidentes.

$\mathrm{Na}$ tentativa de compreender as causas e as tendências do comportamento dos motoristas que se expõe ao risco de acidente de trânsito, diferentes perspectivas teóricas e metodológicas procuraram estudar esse fenômeno. Um dos primeiros registros desenvolvido por Grenwood e Woods, no ano de 1919 (citados por Hale \& Hale, 1972), foi a teoria Teoria da Propensão ao Acidente, esse estudo relacionava os AT com os acidentes de trabalho; outra pesquisa foi a de Tillman e Hobbes (1949), que investigaram os motoristas de táxi envolvidos em acidentes, tinham anteriormente ao fato, apresentado comprometimento com a justiça e com outros órgãos de assistência do governo.

Na década de 70, os estudos do Transport Road Research Laboratory em Londres e na Universidade de Indiana, para o Departament of Transpotation dos Estados Unidos, por Sabey e Staughton, entre março de 1970 a abril de 1974, concluíram que as falhas eram principalmente dos condutores (citados por Rozestraten, 1988). Entre 1972 a 1977, a Universidade de Indiana investigou os acidentes por meio de Boletim de Ocorrência, o resultado deste estudo indicou o fator humano com 79,3\% como causa de acidente (Rozestraten, 1988). No Brasil, também foi realizada uma investigação, com base nos dados de 100 óbitos no trânsito, pela Diretoria-Geral de Trânsito de São Paulo no ano de 1972, concluíram que $70 \%$ do que foram atribuídas as falhas humanas (Campos, 1978).

No início da década de 70, observou-se o desenvolvimento de teorias que justificassem a ocorrência de acidentes. Wilde (2005) desenvolveu a teoria do risco, que ficou denominada como Teoria da Homeostase. De acordo com o autor, o indivíduo busca certo nível ótimo de risco, denominando-o de risco aceito, tolerado ou pretendido.

As condutas de risco no trânsito têm sido consideradas como variáveis relacionadas aos problemas de comportamento psicossocial. A Teoria da Conduta Problema fundamenta com algumas pesquisas realizadas com motoristas jovens, nessa teoria os comportamentos percebidos como problema se inter-relacionam por meio de um único motivo subjacente e as causas são influenciadas pela 
personalidade, pelo ambiente e pela conduta (Elander, West \& French, 1993; Jessor, 1987).

Com os resultados desses estudos, pode-se considerar que muitos fatores influenciam no complexo processo de tomada de decisão do condutor. As condições emocionais e de saúde do condutor também podem afetar suas habilidades no processamento das informações necessárias e nessas circunstâncias, o erro é denominado como causa indireta (Gonzáles \& Hoffmann, 2004). A percepção da alteração do humor, após permanecerem muito horas dirigindo, foi identificada no relato de motoristas que relataram cometer violação no trânsito (Reason, Manstead, Stradling, Baxter \& Campbell, 1990).

Parker, Reason, Mansted e Stradling (1995) distinguem o erro no trânsito em dois comportamentos distintos, o erro como um desvio de uma ação planejada, um deslize e o erro como violação. Na violação está presente uma intenção do comportamento, caracterizando ações deliberadas que se contrapõem a códigos legais ou de condutas socialmente não aceitas. Quando obtiveram os motivos que causaram os acidentes, o fator violação ou causas indiretas foram de maior prevalência em relação aos deslizes. Esses fatores podem ser evidenciados no estudo realizado com 290 alunos do curso de Medicina da Universidade de Londrina, o propósito era de monitorar uma série de comportamentos que podem afetar a saúde, nas questões relacionadas ao conduta no trânsito, $16,7 \%$ responderam que sempre respeitam o limite de velocidade, $12 \%$ relataram que se envolveram em acidentes e $22,5 \%$ dos que se acidentaram indicaram como um fator contribuinte foi o excesso de velocidade (Andrade, Soares, Braga, Morbra \& Botelho, 2003). Stocco, Leite, Labiak e Virgens (2007) aplicaram o mesmo questionário aos estudantes da Universidade de Ponta Grossa, numa amostra de 467 alunos. Nas respostas sobre exceder a velocidade, $46,89 \%$ indicaram que nem sempre respeitam o limite, desse grupo $32,17 \%$ se envolveram em acidentes, indicando na correlação uma significância estatística $(\rho=0,0047)$.

Deve-se ressaltar que tanto o erro quanto as violações têm procedência psicológica (Reason et al, 1990). O erro está relacionado às características de processamento de informação, enquanto que a violação requer fatores motivacionais, portanto, é considerada como desvio de conduta normativa, perpassa a estrutura e a política da organização no trânsito (Lawton, Parker, Manstead \& Stradling, 1997). A violação está sob a influência dos afetos 
humanos, os quais geram comportamento transgressor (Lajunen, Parker \& Stradling, 1998; Lawton et al, 1997).

De acordo com Vasconcelos (1998), o trânsito é uma negociação coletiva e conflituosa pela disputa de espaço, de tempo e do acesso aos equipamentos urbanos, portanto, as condições desse espaço podem instigar o comportamento de cada motorista, o qual depende da complexidade de fatos ligados aos fatores de necessidades interpessoais. No trânsito, Tebaldi e Ferreira (2004) consideram que as diferentes experiências de vida, cultura, ideais e valores, influem também notoriamente na forma adotada de conduzir.

Na disputa por espaço podem surgir divergências de idéias, de valores e de cultura, acarretando nervosismo, ansiedade e agressividade nos motoristas (Tebaldi \& Ferreira, 2004). Como aponta a pesquisa de Macêdo (2005), numa investigação por meio da Escala de Irritabilidades dos Motoristas, com condutores da cidade de São Paulo, verificou que essa amostra pode se irritar muito ou extremamente com situações que observam descortesia no trânsito, especificamente quando percebem que o outro motorista dirige próximo ao párachoque traseiro e respectivamente quando são "fechados/trancados" numa rodovia

Monteiro e Günter (2006) investigaram as relações entre a agressividade, raiva na direção e erros e violações de motoristas, na cidade de Brasília, com 923 motoristas. Como resultado da pesquisa na correlação canônica, com base em três fatores mais incidentes, impedimento do veículo progredir, direção de outro motorista e incomodo no ambiente físico, averiguou-se que quanto menor o índice de raiva na direção, menor o índice de erro e violação agressiva e agressiva interpessoal. No entanto, nos casos em que o índice de raiva na direção foi maior, somente houve o aumento no índice de violação agressiva interpessoal e quando apontou menor índice de raiva na direção provocada pela direção agressiva de outros motoristas, menor foi o índice de violação e erros relatados. Os menores índices de agressividade verbal e irritabilidade estão relacionados a menores indicadores de raiva nos três fatores apresentados pela amostra, também revelando menores os índices de violação e erros dos motoristas (Monteiro \& Günter, 2006).

Numa análise de 36 estudos empíricos nacionais e internacionais, Magalhães e Loureiro (2007) verificaram pesquisas entre o ano de 2000 e 2006, doze são estudos sobre aspectos psicológicos, sendo sete específicos sobre a 
irritabilidade, dois sobre a agressividade e três abordam os dois assuntos. A conclusão da pesquisa assinala que a agressividade é uma tendência ao desrespeito às normas de trânsito vigentes, utilizando o veículo como uma forma de agredir a si e a sociedade. A irritabilidade foi definida como pouca tolerância e hostilidade diante das características rotineiras de organização do trânsito, sendo este caracterizado como um importante fator estressor para o condutor.

Os estudos têm sugerido que existe relação entre os fatores da personalidade e condutas no trânsito. Portanto, teoricamente os motoristas que excedem a velocidade estão violando a conduta, logo, supõe-se que possam ser mais agressivos tanto de maneira instrumental e/ou com tendência a ser hostil, conduzindo o veículo de forma arriscada. A associação entre determinados fatores da personalidade pode indicar uma possibilidade de agir com condutas arriscadas e com maior probabilidade de acidentes quando houver uma interrelação com o meio.

Entender o mecanismo intrínseco do infrator tem sido um desafio na área de trânsito. No Brasil há um conjunto de informações partindo de pressupostos teóricos e dados estatísticos referentes ao perfil dos motoristas acidentados que não se cruzam. Portanto, as pesquisas permitirão verificar se existem e quais são os indicadores da personalidade que implicam em condutas de risco no trânsito. Em relação à Psicologia, quase todos os seus campos oferecem elementos que podem ser aproveitados na solução desses problemas. O desenvolvimento de atividades e recursos eficazes pelos psicólogos possibilitará a concretização da área da Psicologia do Trânsito, o que poderá contribuir para o estudo fundamental e teórico do comportamento humano e processos psíquicos aí implicados (Rozestraten, 1988).

No momento, alguns centros de pesquisas como o Núcleo de Pesquisa em Trânsito da Universidade Federal do Paraná têm realizados estudos sobre o comportamento humano no trânsito, porém a atuação dos psicólogos no trânsito está mais conhecida na avaliação de condutores, selecionando os motoristas que preenchem os supostos requisitos, de aspectos psicológicos para dirigir um veículo de maneira segura. Esta atuação sofreu crítica pela sociedade por considerar como uma medida ineficaz, para a redução de acidentes (Solero, 1986), pela escassez de estudos, ausência de critérios para a escolha de instrumentos de avaliação psicológica e insuficiência nos estudos referentes à validade preditiva e validade simultânea (Alchieri \& Stroeher, 2002). Essa 
situação, não ficou restrita a avaliação psicológica no trânsito; também em outras pesquisas sobre os testes psicológicos foram encontrados os mesmos e outros problemas (Azevedo, Almeida, Pasquali \& Veiga, 1996; Hutz \& Bandeira, 1993; Noronha, 1999). Frente a essa situação, o CFP promulgou a resolução nº 002/2003, medida que promoveu alguns estudos de validação com técnicas psicológica utilizadas para avaliar condutores (Almeida, Alves, Bardella \& Esteves, 2004; Alves \& Esteves, 2004; Lamounier, 2005; Presa, 2002).

Os estudos de evidências de validade forneceram credibilidade ao uso do instrumento, oferecendo subsídios adequados para uma intervenção, quando esta se fizer necessária, e possibilitará ao profissional maior segurança na avaliação psicológica dos candidatos à Carteira Nacional de Habilitação. Devido à carência de técnicas com validade no contexto do trânsito e pelos vários estudos que foram citados indicando a agressividade e a irritabilidade como fator da personalidade propulsor de violações no trânsito, torna-se relevante investigar se os condutores que violam as leis de trânsito apresentam uma personalidade mais agressiva e/ou de maior irritabilidade.

Alguns estudos com testes psicológicos evidenciaram dados de agressividade em motoristas infratores e em condutores que se envolveram em acidentes (Alves \& Esteves, 2004; Grisci, 1991; Lamounier, 2005; Presa, 2002). Uma das técnicas que permite verificar essas variáveis é o Teste das Pirâmides Coloridas de Pfister (TPC). No entanto, o referido instrumento não possui ainda estudos de evidências de validade com motorista, porém, apresenta pesquisas comparando grupos critérios com resultados significativos do ponto de vista estatístico e alguns confirmaram as hipóteses diagnósticas, indicando que a técnica permite evidenciar diferenças entre os grupos pelo uso das cores e pelo aspecto formal (Oliveira, Pasian \& Jacquemin, 2001; Villemor-Amaral, Silva \& Primi, 2002, 2003; Villemor-Amaral, Farah \& Primi, 2004; Villemor-Amaral, Primi, Farah, Silva, Cardoso \& Franco, 2004).

O TPC fornece informações que estão relacionadas ao controle emocional. No caso da irritabilidade e da agressividade pode ser identificada com o aumento da cor Vermelha na tonalidade 2, acompanhada da diminuição do Azul, tons enegrecidos e fórmulas que indicam certa capacidade de contenção. Outro fator que pode ser indício de irritabilidade impedido a elaboração de idéias, é a dupla de Verde rebaixado e Vermelho aumentado. Somente a redução da cor Verde tem um significado negativo, pois indica certa insensibilidade emocional 
diminuindo a abertura para os relacionamentos com possível retraimento social (Villemor-Amaral, 2005).

O aumento do Amarelo sem a Síndrome de Dinamismo também pode reforçar a hipótese de irritabilidade e indica sinais de imaturidade. Por esse indicador ainda é possível uma suspeita de uma estrutura pouco sólida e uma baixa tolerância à frustração. Ao contrário, a ausência ou diminuição do Amarelo indica uma possível dificuldade de canalizar e expressar as emoções de maneira adaptada, considerando outros indicadores do TPC (Villemor-Amaral, 2005).

No conjunto de cores, a irritabilidade pode aparecer na Síndrome do Conflito, porém, leva-se em conta o rebaixamento das cores Amarelo e Laranja. Essa síndrome é forte referência de irritabilidade e impulsividade em pessoas com a estrutura enfraquecida. A formação dessa síndrome se dá por Branco aumentado, Vermelho aumentado e também pelo aumento do Cinza (VillemorAmaral, 2005). Somente o aumento da cor Branca aponta para vulnerabilidade e ausência suficiente de mecanismos de controle, com reações imprevisíveis. 0 aumento da cor Vermelha está associado à extroversão, irritabilidade, impulsividade e agressividade. O aumento da cor Cinza implica numa possível timidez com restrição nos contatos sociais como retraimento defensivo (VillemorAmaral, 2005).

Além do Vermelho 2, já citado, a dupla Vermelho de tonalidade 2 e Violeta de tonalidade 2, também indica agressividade com descarga explosiva e imprevisível, isso quando nas pirâmides não houver indicadores de contenção. Ressalta-se que a cor Violeta tonalidade 2, quando aumentada, aponta para uma possível insatisfação e atitudes imprevisíveis (Villemor-Amaral, 2005).

Outro sinal de agressividade, caracterizando maior violência e explosividade nas descargas emocionais é verificado com a presença da Síndrome de Histeria, composta pelas cores Verde aumentado, Vermelho aumentado e Violeta aumentado. Ao decompor as cores, somente o Verde aumentado sugere ansiedade provocando ruptura do equilíbrio interno, Vermelho aumentado é indicador de irritabilidade e agressividade e Violeta aumentado indica ansiedade difusa, ansiedade excitada, com propensão a atitudes imprevisíveis ou até a contenção (Villemor-Amaral, 2005).

O objetivo geral do presente estudo foi o de buscar evidências de validade do Teste das Pirâmides Coloridas de Pfister (Villemor-Amaral, 2005) como um instrumento que avalie a agressividade e a irritabilidade em motorista 
que excederam velocidade. Como objetivos específicos procuro-se verificar evidências de validade baseada no teste-critério concorrente, por meio do Teste das Pirâmides de Pfister (Villemor-Amaral, 2005), em motoristas infratores e não-infratores e verificar evidências de validade baseada no teste-critério concorrente, por meio do Teste das Pirâmides de Pfister (Villemor-Amaral, 2005), em motoristas infratores e não-infratores.

\section{MÉTODO}

\section{Participantes}

Participaram da pesquisa 100 motoristas da Cidade de Curitiba. Como grupo critério para as análises foram motoristas infratores e não-infratores, com categoria $A B$ e $B$, com mais de cinco anos de habilitação. Para tornar o grupo homogêneo foram definidos alguns requisitos, o grupo dos infratores foi composto de motoristas que participaram do Curso de Reciclagem por ter obtido três ou mais infrações por ultrapassar o limite da via em até 50\%, e os nãoinfratores compunha-se de motoristas que não possuíam infração, não se envolveram em acidentes e não assumiram pontuação de outras pessoas

\section{Instrumentos}

Para coleta de dados foram utilizados um questionário sociodemográfico, o TPC, O IHM, O QCM e a EIM. O Questionário Sociodemográfico contém idade, sexo, estado civil, escolaridade, profissão, tempo de habilitação, quantidade de infração (no caso de infratores), aspectos relacionados à direção e itens sobre a saúde.

O Teste das Pirâmides Coloridas de Pfister é constituído por três cartelas e cada uma contém uma pirâmide dividida em 15 quadrículos, cada um medindo $2,5 \mathrm{~cm}^{2}$. Ainda possui um jogo de quadrículos com 10 cores subdivididas em 24 tonalidades, havendo no mínimo 45 unidades de cada tom, folha de protocolo e mostruário de cores. Para a anotação das cores e da tonalidade existe um mostruário e para avaliação uma folha de protocolo.

O participante preenche uma pirâmide com os quadrículos usando as cores que quiser, após o término faz uma segunda e, em seguida, a terceira. As instruções são simples e devem ser dadas de forma padronizada. O tempo de aplicação é livre, porém, normalmente não ultrapassa mais de 15 minutos. 
O Inventário de Habilidade do Motorista (IHM) contém 25 itens que correspondem a 14 itens de habilidade de direção e 11 que correspondem a situações no trânsito. O participante escolhe dentro de uma escala de 0 ("bem abaixo da média") a 4 ("bem acima da média") conforme a percepção das habilidades e conduta no trânsito. Esse instrumento tem como finalidade avaliar o nível de habilidade perceptomotora e de direção segura.

O Questionário do Comportamento do Motorista possui 20 afirmações, indicando sete relacionadas a violações do Código de Trânsito, cinco a comportamento agressivo e oito itens que indicam erros. As afirmações são niveladas pelo motorista a partir de uma escala que varia de 0 ("nunca") a 5 ("quase o tempo todo"). O QCM permite registrar freqüência de violação (código de trânsito e conduta agressiva).

A Escala de Irritabilidade do Motorista apresenta 27 itens, distribuídos em seis subescalas; seis referindo-se a direção lenta, quatro sobre direção ilegal, oito abordando conduta de descortesia, três sobre atitude de gestos hostis, dois referindo-se a presença de policial e um sobre situação de obstrução do tráfego. A escala deve ser estimada pelo participante em quatro níveis, do nível 0 ("nem um pouco irritado") a 4 ("extremamente irritado"). Essa escala indica fatores que contribuem com a irritabilidade do motorista.

\section{Procedimentos}

As aplicações foram realizadas por dois psicólogos, em uma única sessão, individualmente, dentro da própria Instituição e em uma sala reservada específica para a coleta de dados. Para assegurar o sigilo das informações obtidas nas pesquisas, todos os participantes preencheram o Termo de Consentimento Livre e Esclarecido.

Com o término da coleta de dados, iniciou-se o estudo de precisão entre avaliadores com $20 \%$ dos protocolos do TPC, escolhido por sorteio. Os demais protocolos foram avaliados pela pesquisadora com orientação de uma especialista no teste, devido à ausência e moderada concordância em alguns itens obtidos nas análises entre os juízes.

\section{RESULTADOS}

Em relação aos dois grupos, a escolaridade variou de Ensino Fundamental incompleto até cursos de Pós-Graduação. No grupo de renovação $58 \%$ concluiu o 
terceiro grau, sendo $2 \%$ pós-graduados, $30 \%$ com ensino médio completo e $12 \%$ com escolaridade inferior a esta. O perfil dos infratores indica que $72 \%$ possuem terceiro grau completo, destes $32 \%$ são pós-graduando, $18 \%$ têm o ensino médio completo e $10 \%$ com escolaridade inferior a esta.

Com relação ao tempo de $\mathrm{CNH}$, no grupo de motoristas infratores foi de 5 até 40 anos, nos motoristas não-infratores de 5 até 34 anos. No que diz respeito à da idade, ambos os grupos foram semelhantes. Por sua vez, na variável sexo, o grupo de motoristas infratores foi composto em sua maioria por homens 42, enquanto que, o grupo de motoristas não-infratores apresentou aproximadamente a mesma quantidade de homens 23 e de mulheres 27.

Tanto nas análises das variáveis do TPC que indicam agressividade e irritabilidade quanto nas que indicam contenção, não foram encontradas diferenças significativas estatísticas. Para tanto, foi usado o teste Qui-Quadrado.

Análise da Correlação entre as variáveis do TPC com os instrumentos QCM e EIM

Com o objetivo de verificar se existe relação entre as variáveis do TPC, escolhidas como hipótese na pesquisa, e os resultados do IHM, QCM e EIM, foi utilizado a correlação com o coeficiente de Pearson. Na associação do IHM com as variáveis do TPC não houve nenhuma correlação. As respostas referentes ao comportamento da amostra no trânsito e a relação das escolhas dos indicadores do TPC são apresentadas na Tabela 1.

Em relação ao QCM e o TPC foram verificadas 40 possibilidades de constatar se existe uma relação entre as respostas dos motoristas infratores e não-infratores com os indicadores do TPC. Desta análise resultaram duas correlações estatisticamente significativas. A primeira refere-se à Violação do Teor Agressivo e a Síndrome de Conflito, ou seja, as respostas de Violação de Teor Agressivo indicaram correlação com a Síndrome de Conflito. E a relação entre o resultado do Total da média das Violações com a Síndrome de Conflito. 
Tabela 1.

Correlação entre a QCM e os indicadores do TPC obtidos no total da amostra.

\begin{tabular}{lcccccc}
\hline Pfister & & $\mathrm{E}$ & $\mathrm{VCT}$ & $\mathrm{VTA}$ & $\mathrm{TOTV}$ & $\mathrm{TOTAL}$ \\
\hline Soma do Vermelho & $r$ & & & & & \\
tonalidade 2 & & $-0,01$ & 0,07 & $-0,02$ & 0,04 & 0,03 \\
& $p$ & 0,941 & 0,475 & 0,851 & 0,695 & 0,792 \\
Soma do Violeta & $r$ & & & & & \\
tonalidade 2 & & $-0,15$ & $-0,09$ & $-0,11$ & $-0,11$ & $-0,15$ \\
& $p$ & 0,128 & 0,393 & 0,268 & 0,258 & 0,150 \\
Vermelho & $r$ & $-0,04$ & $-0,01$ & $-0,07$ & $-0,04$ & $-0,04$ \\
& $p$ & 0,717 & 0,915 & 0,520 & 0,695 & 0,665 \\
Amarelo & $r$ & 0,15 & 0,14 & 0,01 & 0,10 & 0,13 \\
& $p$ & 0,144 & 0,164 & 0,905 & 0,315 & 0,187 \\
Verde rebaixado e & $r$ & & & & & \\
Vermelho aumentado & & $-0,02$ & $-0,01$ & 0,11 & 0,05 & 0,03 \\
& $p$ & 0,845 & 0,955 & 0,292 & 0,629 & 0,776 \\
Síndrome da Histeria & $r$ & $-0,06$ & $-0,11$ & $-0,08$ & $-0,11$ & $-0,11$ \\
& $p$ & 0,549 & 0,272 & 0,457 & 0,264 & 0,286 \\
Síndrome do Conflito & $r$ & & & & & \\
Interno & & $-0,03$ & 0,08 & $\mathbf{0 , 3 4}$ & $\mathbf{0 , 2 2}$ & 0,15 \\
& $p$ & 0,762 & 0,429 & $\mathbf{0 , 0 0 1}$ & $\mathbf{0 , 0 2 6}$ & 0,126 \\
Síndrome do Dinamismo & $r$ & 0,02 & $-0,01$ & 0,06 & 0,03 & 0,03 \\
& $p$ & 0,856 & 0,935 & 0,533 & 0,800 & 0,795 \\
\hline
\end{tabular}

LEGENDA: E=Erro; VCT=Violação do Código de Trânsito; VTA=Violação de Teor Agressivo; TOTV=Total de Violação

Ao averiguar somente os motoristas infratores observa-se, nesta amostra, correlação com a Síndrome do Conflito. Os dados podem ser vistos na Tabela 2. Nessa Tabela podem ser observadas 40 possibilidades de correlação. Dessa análise indica que existe a correlação entre a formação da Síndrome do Conflito do Interno e a Violação do Teor Agressivo, especificamente nos motoristas infratores. Essa relação mostrou-se estatisticamente significativa. Na seqüência foram analisados os resultados do EIM e das variáveis do TPC, os quais apresentaram algumas correlações entre as variáveis dos instrumentos. 
Tabela 2.

Correlação entre a QCM e os indicadores do TPC obtidos da amostra dos motoristas infratores.

\begin{tabular}{|c|c|c|c|c|c|c|}
\hline Pfister & & $E$ & VCT & VTA & TOTV & TOTAL \\
\hline \multirow{2}{*}{$\begin{array}{l}\text { Soma do Vermelho } \\
\text { tonalidade } 2\end{array}$} & $r$ & 0,05 & 0,17 & 0,04 & 0,14 & 0,13 \\
\hline & $p$ & 0,742 & 0,230 & 0,773 & 0,347 & 0,358 \\
\hline \multirow{2}{*}{$\begin{array}{l}\text { Soma do Violeta } \\
\text { tonalidade } 2\end{array}$} & $r$ & $-0,02$ & 0,04 & 0,00 & 0,03 & 0,01 \\
\hline & $p$ & 0,879 & 0,803 & 0,976 & 0,858 & 0,928 \\
\hline \multirow[t]{2}{*}{ Vermelho } & $r$ & $-0,19$ & $-0,13$ & $-0,19$ & $-0,19$ & $-0,23$ \\
\hline & $p$ & 0,185 & 0,372 & 0,180 & 0,189 & 0,102 \\
\hline \multirow[t]{2}{*}{ Amarelo } & $r$ & 0,12 & 0,02 & 0,01 & 0,02 & 0,06 \\
\hline & $p$ & 0,185 & 0,372 & 0,180 & 0,189 & 0,102 \\
\hline \multirow{2}{*}{$\begin{array}{l}\text { Verde rebaixado e } \\
\text { Vermelho aumentado }\end{array}$} & $r$ & 0,05 & 0,15 & 0,38 & 0,31 & 0,27 \\
\hline & $p$ & 0,748 & 0,294 & 0,006 & 0,031 & 0,054 \\
\hline \multirow[t]{2}{*}{ Síndrome da Histeria } & $r$ & $* * *$ & $* * *$ & $* * *$ & $* * *$ & $* * *$ \\
\hline & $p$ & $* * *$ & $* * *$ & $* * *$ & $* * *$ & $* * *$ \\
\hline \multirow{2}{*}{$\begin{array}{l}\text { Síndrome do Conflito } \\
\text { Interno }\end{array}$} & $r$ & $-0,08$ & 0,05 & 0,42 & 0,26 & 0,18 \\
\hline & $p$ & 0,570 & 0,752 & 0,002 & 0,071 & 0,203 \\
\hline \multirow{2}{*}{$\begin{array}{l}\text { Síndrome do } \\
\text { Dinamismo }\end{array}$} & $r$ & $-0,05$ & $-0,06$ & 0,14 & 0,03 & 0,01 \\
\hline & $p$ & 0,733 & 0,669 & 0,346 & 0,819 & 0,955 \\
\hline
\end{tabular}

*** não pode ser analisada por não apresentar variável

LEGENDA: E=Erro; VCT=Violação do Código de Trânsito; VTA=Violação de Teor Agressivo; TOTV=Total de Violação

A análise de correlação entre a EIM e o TPC, apresentada na Tabela 3, indicou 56 possibilidades de correlação entre os dois instrumentos. Como resultado foi encontrado a relação entre Gestos Hostis e a Síndrome do Conflito, e os Gestos Hostis com uso reduzido da cor Amarela, ou seja, os indivíduos que responderam que se irritam com Gestos Hostis no trânsito, correspondem aos mesmos que apresentaram a Síndrome do Conflito e usaram de maneira reduzida a cor Amarela. Estatisticamente na relação entre Gestos Hostis e a Síndrome de Conflito Interno é significativa e direta, já na segunda, a relação é significativa e inversa. 
Tabela 3.

Correlação entre EIM e os indicadores do TPC no total da amostra.

\begin{tabular}{|c|c|c|c|c|c|c|c|c|}
\hline Pfister & & DLPON & DIPON & DESPON & GHPON & PPPON & OTPON & TOTAL \\
\hline \multirow{2}{*}{$\begin{array}{l}\text { Soma do Vermelho } \\
\text { tonalidade } 2\end{array}$} & $r$ & $-0,07$ & $-0,03$ & 0,10 & $-0,03$ & 0,03 & 0,02 & 0,00 \\
\hline & $p$ & 0,472 & 0,784 & 0,303 & 0,738 & 0,774 & 0,850 & 0,992 \\
\hline \multirow{2}{*}{$\begin{array}{l}\text { Soma do Violeta } \\
\text { tonalidade } 2\end{array}$} & $r$ & $-0,06$ & 0,01 & 0,07 & $-0,08$ & 0,01 & $-0,02$ & $-0,03$ \\
\hline & $p$ & 0,543 & 0,896 & 0,488 & 0,425 & 0,957 & 0,813 & 0,802 \\
\hline \multirow[t]{2}{*}{ Vermelho } & $r$ & 0,12 & 0,18 & 0,05 & 0,03 & $-0,02$ & 0,14 & 0,12 \\
\hline & $p$ & 0,220 & 0,071 & 0,592 & 0,767 & 0,814 & 0,171 & 0,227 \\
\hline \multirow[t]{2}{*}{ Amarelo } & $r$ & $-0,11$ & $-0,05$ & 0,05 & $-0,21$ & $-0,03$ & 0,06 & $-0,07$ \\
\hline & $p$ & 0,262 & 0,644 & 0,615 & 0,032 & 0,782 & 0,538 & 0,473 \\
\hline \multirow{2}{*}{$\begin{array}{l}\text { Verde rebaixado e } \\
\text { Vermelho } \\
\text { aumentado }\end{array}$} & $r$ & 0,02 & 0,08 & 0,10 & 0,01 & $-0,07$ & 0,04 & 0,05 \\
\hline & $p$ & 0,86 & 0,41 & 0,34 & 0,94 & 0,48 & 0,70 & 0,65 \\
\hline \multirow{2}{*}{$\begin{array}{l}\text { Síndrome da } \\
\text { Histeria }\end{array}$} & $r$ & 0,638 & 0,608 & 0,766 & 0,617 & 0,757 & 0,895 & 0,742 \\
\hline & $p$ & 0,64 & 0,61 & 0,77 & 0,62 & 0,76 & 0,90 & 0,74 \\
\hline \multirow{2}{*}{$\begin{array}{l}\text { Síndrome do } \\
\text { Conflito Interno }\end{array}$} & $r$ & 0,05 & 0,10 & 0,12 & 0,28 & 0,00 & 0,05 & 0,15 \\
\hline & $p$ & 0,637 & 0,323 & 0,222 & 0,013 & 0,995 & 0,593 & 0,138 \\
\hline \multirow{2}{*}{$\begin{array}{l}\text { Síndrome do } \\
\text { Dinamismo }\end{array}$} & $r$ & $-0,05$ & 0,00 & 0,07 & $-0,12$ & $-0,10$ & $-0,08$ & $-0,07$ \\
\hline & $p$ & 0,626 & 0,982 & 0,483 & 0,237 & 0,341 & 0,431 & 0,493 \\
\hline
\end{tabular}

$\mathrm{Na}$ Tabela 4 podem ser observadas as relações encontradas entre o EIM e o TPC, conforme os dados obtidos somente dos motoristas infratores. A análise do EIM com o TPC permitiu 56 possíveis correlações.

Ao correlacionar o EIM com o TPC, verificou-se que os motoristas infratores apresentaram relação entre as duplas de Verde rebaixado e Vermelho aumentado com Direção Ilegal, Descortesia e Gestos Hostis. Ainda a variável Síndrome do Conflito Interno obteve relação linear com os Gestos Hostis, como se pode observar na tabela, as correlações foram estatisticamente significativas. 
Tabela 4.

Correlação entre EIM e os indicadores do Pfister obtidos da amostra dos motoristas infratores.

\begin{tabular}{|c|c|c|c|c|c|c|c|c|}
\hline Pfister & & DLPON & DIPON & DESPON & GHPON & PPPON & OTPON & TOTAL \\
\hline \multirow{2}{*}{$\begin{array}{l}\text { Soma do } \\
\text { Vermelho } \\
\text { tonalidade } 2\end{array}$} & $p$ & 0,07 & 0,09 & 0,21 & 0,08 & 0,24 & $-0,06$ & 0,12 \\
\hline & $r$ & 0,620 & 0,553 & 0,146 & 0,561 & 0,096 & 0,706 & 0,412 \\
\hline \multirow{2}{*}{$\begin{array}{l}\text { Soma do Violeta } \\
\text { tonalidade } 2\end{array}$} & $p$ & 0,02 & $-0,15$ & 0,02 & $-0,22$ & 0,22 & $-0,02$ & $-0,07$ \\
\hline & $r$ & 0,872 & 0,297 & 0,887 & 0,133 & 0,134 & 0,900 & 0,653 \\
\hline \multirow[t]{2}{*}{ Vermelho } & $p$ & $-0,07$ & $-0,06$ & $-0,17$ & $-0,09$ & $-0,07$ & $-0,02$ & $-0,10$ \\
\hline & $r$ & 0,634 & 0,700 & 0,239 & 0,556 & 0,631 & 0,893 & 0,481 \\
\hline \multirow[t]{2}{*}{ Amarelo } & $p$ & 0,00 & 0,03 & 0,17 & $-0,06$ & 0,13 & 0,15 & 0,09 \\
\hline & $r$ & 0,975 & 0,841 & 0,245 & 0,693 & 0,352 & 0,295 & 0,536 \\
\hline \multirow{2}{*}{$\begin{array}{l}\text { Verde rebaixado e } \\
\text { Vermelho } \\
\text { aumentado }\end{array}$} & $p$ & 0,27 & 0,36 & 0,39 & 0,31 & 0,11 & 0,21 & 0,39 \\
\hline & $r$ & 0,055 & 0,009 & 0,006 & 0,029 & 0,444 & 0,135 & 0,005 \\
\hline \multirow{2}{*}{$\begin{array}{l}\text { Síndrome da } \\
\text { Histeria }\end{array}$} & $p$ & $* * *$ & $* * *$ & $* * *$ & $* * *$ & $* * *$ & $* * *$ & $* * *$ \\
\hline & $r$ & $* * *$ & $* * *$ & $* * *$ & $* * *$ & $* * *$ & $* * *$ & $* * *$ \\
\hline \multirow{2}{*}{$\begin{array}{l}\text { Síndrome do } \\
\text { Conflito Interno }\end{array}$} & $p$ & 0,05 & 0,19 & 0,17 & 0,39 & $-0,02$ & 0,07 & 0,22 \\
\hline & $r$ & 0,740 & 0,191 & 0,249 & 0,006 & 0,902 & 0,620 & 0,121 \\
\hline \multirow{2}{*}{$\begin{array}{l}\text { Síndrome do } \\
\text { Dinamismo }\end{array}$} & $P$ & $-0,05$ & 0,02 & 0,08 & $-0,06$ & $-0,06$ & 0,00 & $-0,02$ \\
\hline & $R$ & 0,739 & 0,909 & 0,582 & 0,661 & 0,668 & 0,980 & 0,896 \\
\hline
\end{tabular}

\section{DISCUSSÃO}

Estima-se que 1,2 milhões de pessoas morrem a cada ano nas estradas e que 518 milhões de dólares são gastos em tratamentos (OMS, 2004). No Brasil, os acidentes de trânsito destacam-se como a terceira causa de óbitos, perdendo apenas para as neoplasias e doenças do aparelho circulatório (Ministério da Saúde, 2004). Além do alto índice de óbitos, os problemas se estendem as lesões e deficiências físicas (Almeida \& Freitas, 1995; Sallum \& Koizume, 1999; Weyll, Silveira \& Fonseca, 2005), aos prejuízos econômicos destinada aos recursos da saúde, ocupação nos leitos hospitalares e nas despesas para o atendimento das vítimas (Centro de Pesquisa em Educação e Prevenção na rede SARAH, 2000; Instituto de Pesquisa Econômica Aplicada, 2006). 
Quanto as regras no trânsito a ultrapassagem do limite da via tem sido considerado como uma infração preocupante devido a três fatores: primeiro pelo fato de se apresentar como infração de maior freqüência nas pesquisas (Departamento de Trânsito do Paraná, 2004; Macêdo 2005; Prado, 2005); segundo, nas opiniões de indivíduos que se envolveram em acidentes, este fator contribui para a ocorrência (Andrade et al, 2003); e em terceiro, devido à conseqüência do próprio acidente, resultar em maior número de lesões, fraturas e maior probabilidade de fatalidades (Almeida \& Freitas, 1995).

Nos primeiros estudos de acidentes de trânsitos suspeitava-se que havia uma relação entre os AT e os acidentes de trabalho (citado por Hale \& Hale, 1972) e 30 anos depois, Tillman e Hobbes (1949) procuravam relacionar os motoristas que se envolviam em acidentes com 0 fato de terem comprometimento com a justiça. Os estudos da década 70 foram baseados em dados dos acidentes, boletim de ocorrência in loco, contudo, no Brasil e no exterior, concluiu-se que as falhas humanas são determinantes para a ocorrência dos acidentes (Campos, 1978; Rozestraten, 1988).

Os pesquisadores procuravam uma justificativa para essa falha humana. Wilde (2005) desenvolveu a Teoria da Homeostase e Elander et al (1993) e Jessor (1987) buscavam entender a conduta de risco, especificamente, a Teoria da Conduta Problema. Chegou-se à conclusão de que as causas são determinadas por uma combinação complexa entre personalidade, ambiente e conduta. Por fim, as condições emocionais foram consideradas como fatores que interferem na habilidade do condutor e no processo de tomada de decisão (Gonzáles \& Hoffmann, 2004; Reason, Manstead, Stradling, Baxter \& Campbell, 1990).

Tebaldi e Ferreira (2004) consideram que a conduta no trânsito depende da experiência de vida, ideais e valores. Dessa forma, tanto agir corretamente como infringir as normas no trânsito depende da estrutura emocional do motorista e dos fatores externos no trânsito. Com bases teóricas desenvolvidas sobre condutas erradas no trânsito (Gonzáles \& Hoffmann, 2004; Parker, Reason, Manstead e Stradling, 1995), surge um perfil de motorista que empreende ações arriscadas, e as pesquisas de Andrade et al (2003), Stocco, Leite, Labiak e Virgens (2007) confirmam as hipóteses que a atitude de violação no trânsito predispõe o condutor a envolver-se em acidentes. O levantamento sobre estudos de acidentes de trânsito realizado, por Magalhães e Loureiro 
(2007), confirma que a agressividade e a irritabilidade correlacionam-se de forma significativa entre os motoristas que se envolveram em acidentes de trânsito.

As atitudes de violação no trânsito necessitam de motivação impulsionada pela agressividade (Lawton, Parker, Manstead \& Stradling, 1997), desse modo, estão atreladas à questões psicológicas do condutor. A confirmação ou não da hipótese da agressividade ser propulsora da violação no trânsito, seria viabilizada a partir de pesquisas com instrumentos psicológicos que permitem verificar a relação entre essas variáveis, porém, os estudos dessa natureza são escassos (Alchieri \& Stroeher, 2002). Além de poucas pesquisas, esta área da Psicologia, sofreu críticas pela falta de credibilidade dos instrumentos para verificação de indivíduos propensos a se envolver em acidentes (Solero, 1986). Conforme aponta Rozestraten (1988), quase todos os campos da Psicologia oferecem elementos para auxiliar na solução desses problemas, o desenvolvimento de atividades e recursos eficazes pelos psicólogos possibilitará contribuir para o estudo fundamental e teórico do comportamento humano e processos psíquicos aí implicados.

Em relação ao resultado da população pesquisada, a maioria possui o terceiro grau completo. Quanto ao gênero a maioria dos motoristas infratores pertencia ao sexo masculino, à faixa etária dos motoristas infratores variou entre 24 a 50 anos, a idade média foi de 35,88 , não sendo diferente da dos motoristas não-infratores.

$\mathrm{Na}$ análise entre os grupos, foram utilizadas todas as variáveis de agressividade e irritabilidade do TPC, visto que, muitas teorias propõem que a violação do trânsito está relacionada a essas atitudes (Lawton et al, 1997; Lajunen et al, 1998; Magalhães \& Loureiro, 2007; Tebaldi \& Ferreira, 2004). Mas nas análises das variáveis do TPC que indicam agressividade e irritabilidade e nas que indicam contenção, não foram encontradas diferenças significativas estatísticas, por meio do Qui-Quadrado, entre os motoristas.

Ao correlacionar as variáveis do TPC com QCM, foi possível observar que a variável cor Amarela apresentou correlação inversa no grupo total aos Gestos Hostis (EIM). Esse indicador, quando encontrado de maneira reduzida, supõe uma dificuldade da pessoa em canalizar e expressar as emoções de forma adaptada. No entanto, para a confirmação dessa suspeita deve-se levar em consideração outros fatores do TPC que permitirão afirmar ou não essa 
característica (Villemor-Amaral, 2005). Contudo, cabe esclarecer que esta variável apresentada de forma reduzida não pertence ao grupo de hipóteses do TPC na pesquisa.

Investigando somente o resultado do TPC e EIM dos motoristas infratores, verificou-se que a dupla de Cor Verde rebaixada e Vermelho aumentado apresentaram correlações com a Direção Ilegal, Descortesia, Gestos Hostis. A dupla formada pela cor Verde rebaixada e Vermelho aumentado é um forte indicador de irritabilidade e impulsividade, sem condições de elaboração, o que tende a dificultar a atuação ordenada e coerente (Villemor-Amaral, 2005).

No que se refere ao EIM, a Direção Ilegal indica irritabilidade quando outro motorista desrespeita a lei, Descortesia, diante de situações de falta de gentileza e Gestos Hostis e em circunstâncias que percebem gestos por outro motorista acarretando irritação. Esse resultado propõe que, nas circunstâncias de Direção Ilegal, Descortesia e Gestos Hostis, os motoristas infratores pesquisados estão propensos a maior irritação.

A variável Síndrome do Conflito Interno teve associações com a Violação de Teor Agressivo (QCM) e com o Total de Violação (QCM) na amostra total. Vale salientar que o QCM permite analisar como o motorista se comporta no trânsito. Portanto, a violação nesse contexto refere-se à ações deliberadas que se contrapõem às condutas socialmente aceitas (Lajunen, Parker \& Strandling, 1998) e perpassam as condutas normativas e a estrutura política da organização (Lawton et al, 1997).

A Síndrome do Conflito Interno é um forte indicador de irritabilidade em pessoas com estrutura enfraquecida (Villemor-Amaral, 2005). Esse resultado indica que os motoristas da pesquisa que apresentaram a Síndrome do Conflito Interno, podem ter os mecanismos de controle enfraquecidos e propensos à irritabilidade com tendência a condutas de violação de teor agressivo.

A variável Síndrome do Conflito Interno também teve associação com os Gestos Hostis (EIM) nos motoristas e no grupo específico dos infratores. Com esse resultado, revela que os motoristas da pesquisa que apresentaram a Síndrome do Conflito e relataram irritar-se com os Gestos Hostis, tem maior probabilidade de irritar-se diante de críticas por meios de gestos no trânsito. 


\section{CONSIDERAÇÕES FINAIS}

Em relação aos resultados obtidos do Teste das Pirâmides Coloridas de Pfister com a amostra de motoristas mencionada, foi possível evidenciar indicadores de agressividade e de irritabilidade, embora não tenha sido encontrada diferença na freqüência das variáveis do TPC, entre motoristas infratores e não-infratores. Em relação aos objetivos específicos foram encontradas correlações significativas estatisticamente com a dupla Verde rebaixada e Vermelho aumentado, e a Síndrome do Conflito Interno, indicado que o TPC evidenciou validade concorrente por meio das correlações com QCM e EIM. Os resultados sugerem a sensibilidade do TPC para identificar a irritabilidade e a agressividade, embora somente outros estudos possam evidenciar se a presença desses aspectos constitui fatores de riscos no trânsito.

Muitos estudos apontam que as condutas de violar as normas no trânsito relacionam-se à agressividade e a irritabilidade do motorista, mas identificar essa relação por meio de pesquisa requer certo cuidado. Deve-se considerar variáveis como condições do trânsito, condição do motorista e estrutura de personalidade, para então, compreender e verificar se existe uma relação. Ainda sim, torna-se difícil definir se o condutor infringiu uma lei de trânsito por apresentar uma dinâmica da personalidade mais agressiva, com probabilidade de irritar-se, ou se o motorista infringiu normas no período de crise e mudanças. Estas últimas podem enfraquecer mecanismos de autocontrole frente às exigências do dia-a-dia, não apenas no contexto do trânsito, além, é claro, de se observar as condições da malha viária.

Mediante a esses fatores, destaca-se o quanto é importante o desenvolvimento de pesquisas que indiquem as características psicológicas com maior propensão a condutas de violação no trânsito, associadas com informações específicas, incluindo informações da subjetividade do motorista. A atuação da Psicologia pode se ampliar com atividades que considerem a reciprocidade dos impactos entre indivíduo e ambiente, uma vez que as conjecturas teóricas e o próprio resultado da pesquisa mostram que as condições do trânsito podem alterar o humor do motorista. 


\section{REFERÊNCIAS}

Almeida, Y. D. B., Alves, I. C. B., Bardella, M. B., \& Esteves, C. (2004). Comparação dos resultados do Psicodiagnóstico Miocinético - PMK de Belo Horizonte com os de Recife e de São Paulo. PSIC. Psic - Vetor Editora, 5(2), 36-47.

Almeida, I. S., \& Freitas, M. F. (1995). Óbitos e lesões corporais por acidente de trânsito com vítima em Brasília-DF-em 1990 e sua relação com a velocidade dos veículos envolvidos. Brasília Medicina, 32(2), 13-19.

Alchieri, J. C., \& Stroeher, F. (2002). Avaliação psicológica no trânsito: o estado da arte no Brasil sessenta anos depois. In R. M. Cruz, J. M. Alchieri \& J. J. Sarda (Orgs.), Avaliação e medidas psicológicas - produção de conhecimento e da intervenção profissional (pp. 234-345). São Paulo: Casa do Psicólogo.

Alves, I. C. B., \& Esteves, C. (2004). O Teste Palográfico na avaliação da personalidade. São Paulo: Vetor Editor.

Andrade, S. M., Soares, D. A., Braga, G. P., Morbra, J. H., \& Botelho, F. M. N. (2003). Comportamentos de Risco para Acidentes de Trânsito: Um Inquérito entre Estudantes de Medicina na Região Sul do Brasil. Revista da Associação Médica, 49 (4), 439-443.

Azevedo, M. M., Almeida, L. S., Pasquali, L., \& Veiga, H. M. S. (1996). Utilização dos Testes Psicológicos no Brasil: dados de estudo preliminares em Brasília. In L. S. Almeida; S. Araújo, M. M. Gonçalvez, C. Machado \& M. R. Simões (Orgs.), Avaliação Psicológica: formas e contextos, (vol. IV, pp. 213-220). Braga, Portugal: APPORT.

Campos, F. (1978). O fator humano e os acidentes de trânsito. Arquivo brasileiro de psicologia aplicada, 30, 99-117.

Centro de Pesquisa em Educação e Prevenção da Rede SARAH. (2000). Acidentes de Trânsito - Perfil geral: Caracterização de Pacientes. Prevenção. Recuperado em 5/07/2006 de http://www.sarah.br/prevenção.

Código de Trânsito Brasileiro. (1997). Lei no. 9.503, de 23 de setembro de 1997. Brasília. Recuperado em 23/03/2005 do DENATRAN http://www.denatran.gov.br/CTB.htm 
Conselho Federal de Psicologia. (2003). Define e regulamenta o uso, a elaboração e a comercialização de teste psicológico e revoga a Resolução CFP no. 025/2001. Recuperado em 14/04/2006, do Conselho Federal de Psicologia http://www.pol.org.br

Departamento de Trânsito do Paraná. (2004). Amostragem de Infrações ocorridas no Período: Março à Maio/2004. Coordenadoria de Educação para o Trânsito. Paraná

Elander, J., West, R., \& French, D. (1993). Behavioral correlates of individual differences in road-traffic crash risk : an examination of methods and findings. Psychological bulletin, 11 (2), 279-294.

González, L. M., \& Hoffmann, M. H. (2004). Acidentes de Trânsito e Fator Humano. In J. C. Alchieri, R. M. Cruz \& M. H. Hoffmann (Orgs), Comportamento Humano no Trânsito (pp. 377- 391). São Paulo: Casa do Psicólogo.

Grisci, C. L. I. (1991). Relação entre acidentes de trânsito e as variáveis de agressividade, atuação e culpa. PSICO, 2(1), 103-107.

Hale, A. R., \& Hale, M. (1972). A review of the industrial accident research literature. Her Majesty's Stationery Office (Committee on Safety and Health at Work Research Paper). London.

Hutz, C. S., \& Bandeira, D. R. (1993). Tendências Contemporânea no Uso de Teste: uma análise da literatura brasileira e internacional. Psicologia: reflexão e crítica, 6(1-2), 85-101.

Instituto de Pesquisa Econômica Aplicada - IPEA. (2006). Impactos Sociais e Econômicos dos Acidentes de Trânsito nas Rodovias Brasileiras. Brasília Jessor, R. (1987). Risk driving and adolescent problem-behavior: An extension of problem-behavior theory. Alcohol, drugs, and Driving, 3(3-4), 1- 11

Lajunen, T., Parker, D., \& Stradling, S. G. (1998). Dimensions of driver anger, aggressive and highway code violations and their mediation by safety orientation in UK drivers. Transportation Research Part F, 11(2), 107-121

Lamounier, R. (2005). O Rorchach e a Avaliação de Motoristas: Evidências de validade. Dissertação de Mestrado, USF, Itatiba, São Paulo.

Lawton, R., Parker, D., Manstead, A. S. R., \& Stradling, S. (1997). The Role Of Affetc In Predicting Social Behaviours: The Case Of Road Traffic Violations', Journal Of Applied Social Psychology, 27(14), 1258-1276,. 
Macêdo, G. M. (2005). Estudos das relações entre o nível de habilidade e direção segura, a irritabilidade e cometimento de violação e erros dos motoristas e o seu possível envolvimento com acidentes de trânsito. Tese de Doutorado, USP, São Paulo.

Magalhães, S. H. T., \& Loureiro, S. R. (2007). Acidentes de Trânsito e Variáveis Psicossociais- uma Revisão da Literatura Medicina. Simpósio de Cirurgia de Urgência e Trauma, Ribeirão Preto, 40 (3) 345-51

Marin, L., \& Queiroz, M. S. (2000). A atualidade dos acidentes de trânsito na era da velocidade: uma visão geral. Caderno de Saúde Pública, 16(1), 7-21.

Mauro, M. L. F. (2001). Acidentes de Trânsito: Perfil Epidemiológico de Vítimas e Caracterização de Alguns Traços de Personalidade de Motoristas Infratores em Campinas. Tese, UNICAMP, Campinas, São Paulo.

Ministério da Saúde. (2004). Uma análise da mortalidade no Brasil e Regiões Distribuição das principais causas de morte, Brasil - 1990, 1996 e 2004. Recuperado em 6/07/2005, do Ministério da Saúde http://portal.saude.gov.br/saude/visualizar.

Monteiro, C. A. S., \& Günter, H. (2006). Agressividade, raiva e comportamento do condutor. Psicologia: pesquisa e trânsito, 2(1), 9-17

Noronha, A. P. P. (1999). Avaliação psicológica Segundo psicólogos: usos e problemas com ênfase nos testes. Tese de doutorado. Pontifícia Universidade Católica de Campinas, Campinas.

Oliveira, E. A., Pasian, S. R., \& Jacquemin, A. (2001). A Vivência Afetiva em Idosos. Psicologia Ciência e Profissão, 21(1), 68-83

Organização Mundial da Saúde. (1976). The Epidemiology of Road Traffic Accidents. WHO Regional Publications, European Series 2: Copenhagen.

Organização Mundial da Saúde. (1996). Classificação estatística internacional de doenças e problemas relacionados à saúde (10a ed.). São Paulo: EDUSP.

Organização Mundial da Saúde. (2004). Informe mundial sobre prevencón de los traumatismos causados por el tránsito: resumen. Genebra: The World Bank and World Health Organization.

Organização Panamericana de Saúde. (1994). Las Condiciones de Salud en la Américas. Washington, D.C.

Parker, D., Reason, J. T., Manstead, A., \& Stradling, S. G. (1995). Driving errors, driving violations and accident involvement. Ergonomics, 38(5), 1036-1048. 
Prado, M. M. M. (2005). Estudo para construção de uma escala do medo em situações de trânsito, Dissertação de Mestrado. Universidade São Francisco. Itatiba.

Presa, L. A. P. (2002). Mensuração da raiva em motoristas - STAXI. São Paulo: Vetor Editora.

Reason, J.,Manstead, A., Stradling, S., Baxter, J., \& Campbell, K. (1990). Erros and violations on the roads: real distinction. Ergonomics, 33(10-11), 13151332.

Rozestraten, R. J. (1988). Psicologia do Trânsito-conceitos e processo básicos. São Paulo: EPU.

Sallum, A. M. C., \& Koizume, M. S.(1999). Natureza e gravidade das lesões em vítimas de acidentes de trânsito de veículo a motor. Revista da Escola de Enfermagem, 33(2), 157-164.

Solero, J. (1986). Psicologia em Debate - Psicologia do Trânsito: As alternativas para o psicólogo. Psicologia Ciência e Profissão, 6(2), 18-28.

Stocco, C, Leite, M. L., Labiak, V. B., \& Virgens, J. S. (2007). Comportamentos de Risco no Trânsito entre Estudantes Universitários em Ponta Grossa-Pr. Cogitare Enfermagem, 12(1), 20-29.

Tapia-Granados, J. A. (1998). La reducción del tráfico de automóviles: Una política urgente de promoción de la salud. Revista Panamericana deSalud Pública, (3), 137-151.

Tebaldi, E., \& Ferreira, V. R. T. (2004). Comportamento no trânsito e causas da agressividade. Revista de Psicologia da UnC, 2(1), 15-22.

Tillman, W. A., \& Hobbes, G. E. (1949). The accident-phone automobile driver. American Journal of Psychiatry, 106, 321-331.

Vasconcelos, E. (1998). O que é Trânsito? São Paulo: Brasiliense.

Villemor-Amaral, A. E. (2005). As Pirâmides Coloridas de Pfister. São Paulo: Centro Editor de Testes e Pesquisas em Psicologia.

Villemor-Amaral, A. E, Farah, F. H. Z., \& Primi, R. (2004). O Teste das Pirâmides Coloridas e o Transtorno de Pânico. Psicologia em Estudo, 9(2), 301-307

Villemor-Amaral, A. E., Primi, R., Farah, F. H. Z., Silva, M. S., Cardoso, L. M., \& Franco, R. R. C. (2004). A depressão no teste das Pirâmides Coloridas de Pfister. Ribeirão Preto: Paidéia - Caderno de Psicologia e Educação, 14(28), 169- 176. 
Villemor-Amaral, A. E., Silva, T. C., \& Primi, R. (2002). O Teste das Pirâmides de Pfister e o Transtorno-Obsessivo Compulsivo. Avaliação Psicológica, 1(2), 133-139.

Villemor-Amaral, A. E., Silva, T. C., \& Primi, R. (2003). Indicadores de alcoolismo no Teste das Pirâmides Coloridas de Max Pfister. Psico - USF, 8(1), 33-38.

Weyll, B. G. M., Silveira, C. R., \& Fonseca, N. L. (2005). Trauma ocular aberto: características de casos atendidos no complexo Hospitalar Padre Bento de Guarulhos. Arquivo Brasileiro de Oftalmologia, 68(4), 505-510.

Wilde, G. J. S. (2005). O Limite Aceitável de Risco: Uma nova psicologia sobre segurança e saúde. O que funciona? O que não funciona? E por Que? São Paulo: Casa do Psicólogo.

Contato: joneia.tawamoto@gmail.com,cgcapitao@uol.com.br

Recebido em: 22/03/2010

Revisado em: 18/05/2010

Aceito em: 13/06/2010 